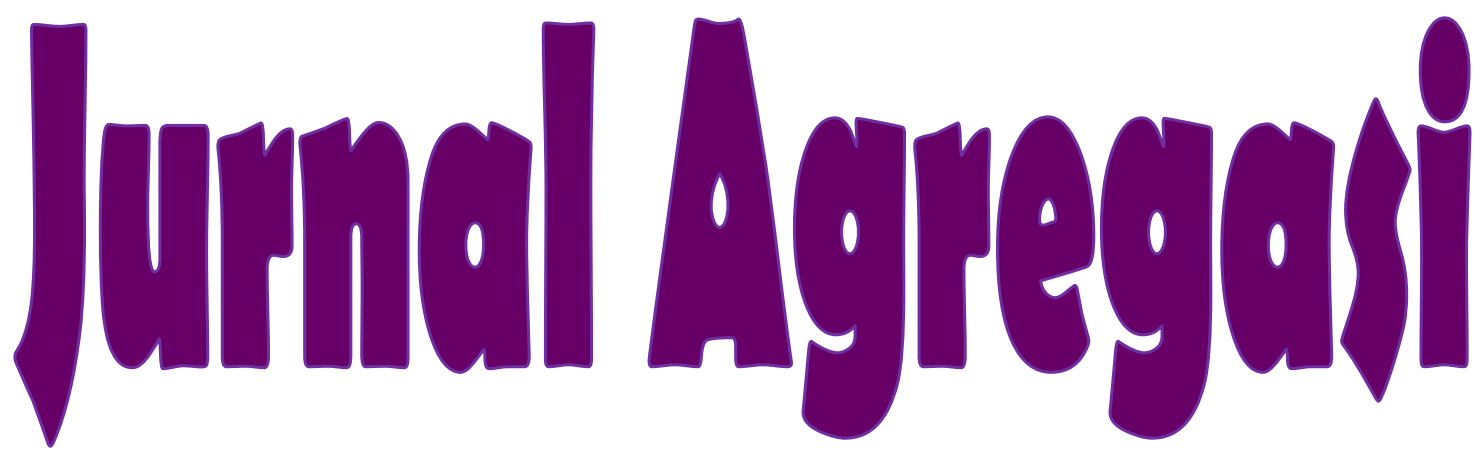

Aksi Reformasi Government dalam Demokrasi

Volume 6 / Nomor 1 / Tahun 2018 / Hal. 1 - 125

Etika Otonomi Daerah Dalam Perspektif Filsafat Pendidikan Fatmawati

Peranan Aparatur Pusat Penelitian dan Pengembangan Daya Air (Puslitbang SDA) dalam Meningkatkan Kualitas Pelayanan Publik Melalui Sistem Informasi Geografis Bidang Sumber Daya Air (SIGSDA) Henri Prianto Sinurat

Revitalisasi Pembangunan Pendidikan Melalui Pendekatan Komunikasi Pendidikan Iwan Koswara

Monitoring dan Evaluasi Pemanfaatan Dana Keistimewaan Daerah Istimewa Yogyakarta Tahun 2013-2017 Laksmi Nurita Tanjung, Dyah Mutiarin dan Eko Priyo Purnomo

Mekanisme Lembaga Adat Melayu Riau dalam Melestarikan Wisata Budaya di Provinsi Riau M.Zainuddin

Implementasi Fungsi Artikulasi dan Agregasi PKS Kota Bandung pada Pemilu 2009 Olih Solihin 


\section{JURNAL AGREGASI}

Merupakan Jurnal Ilmiah berkala yang diterbitkan oleh Program Studi Ilmu Pemerintahan FISIP Unikom. Jurnal ini memuat berbagai hasil penelitian, konsep atau gagasan pemikiran yang terkait dengan reformasi pemerintahan.

\section{DEWAN REDAKSI}

\section{Pembina :}

\section{Dekan FISIP Unikom}

Prof. Dr. Samugyo Ibnu Redjo, Drs., MA.

Penanggung jawab :

Kaprodi Ilmu Pemerintahan Unikom

Dr. Dewi Kurniasih, S.IP., M.Si.

\section{Ketua :}

Nia Karniawati, S.IP.,M.Si.

\section{Mitra Bestari :}

Prof. Dr. Samugyo Ibnu Redjo, Drs.,MA

Prof. Dr. H. Utang Suwaryo, Drs., MA.

Prof. Dr. Cecep Darmawan, S.IP., M.Si.

\section{Tim Editing :}

Dr. Poni Sukaesih K, S.IP.,M.Si.

Tatik Rohmawati, S.IP.,M.Si.

Tatik Fidowaty, S.IP.,M.Si.

Rino Adibowo, S.IP.,M.I.POL

\section{Sekretariat :}

Airinawati, A.Md.

\section{Alamat Redaksi :}

Prodi Ilmu Pemerintahan Unikom

Jl. Dipati Ukur 112-114 Bandung 40132

Telp. 022.2533676 Fax. 022.2506577

OJS : http://ojs.unikom.ac.id/index.php/agregasi

Web : http://jurnalagregasi.ip.unikom.ac.id

Email : jurnalagregasi@email.unikom.ac.id 


\section{KATA PENGANTAR}

Ass. Wr.Wb.

Alhamdulillah, Puji dan Syukur Kita Panjatkan kehadirat Illahi Robbi, atas berkah dan rahmatNya, Jurnal Agregasi Volume 6 Nomor 1 Tahun 2018 dapat kami terbitkan. Jurnal ini merupakan karya ilmiah dari Dosen Ilmu Pemerintahan FISIP Unikom dan Kontributor lain di luar lingkungan Ilmu Pemerintahan FISIP Unikom yang terdiri dari para dosen, pakar maupun praktisi di bidang Pemerintahan.

Dalam Jurnal Agregasi Volume 6 Nomor 1 ini terdapat enam tulisan. Tulisan tersebut merupakan karya ilmiah dari Fatmawati dari STISIP Syamsul Ulum Sukabumi, Henri Prianto Sinurat dari PKP2A IV LAN Banda Aceh, Iwan Koswara dari Unpad Bandung, Laksmi Nurita Tanjung, dkk dari UMY, M.Zainuddin dari Universitas Abdurrab Pekanbaru dan Olih Solihin dari Unikom Bandung. Kepada yang telah berkontibusi memberikan tulisan kami haturkan banyak terima kasih.

Besar harapan kami, karya ilmiah yang terdapat dalam jurnal ini dapat memberikan banyak manfaatnya. Sekian dan terima kasih.

Wss. Wr. Wb.

Bandung, Mei 2018 


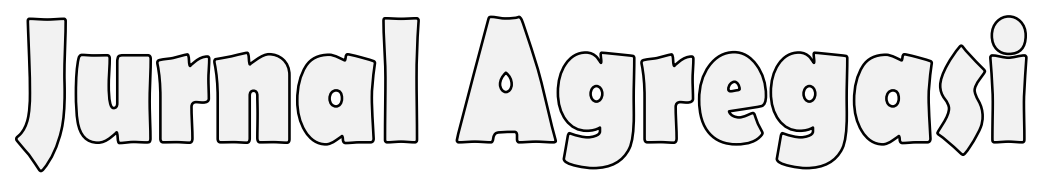

\section{Aksi Reformasi Government dalam Demokrasi \\ e-ISSN: 2579-3047/p-ISSN: 2337-5299/ Vol.6/No.1/Th.2018/Hal.1-125}

\section{DEWAN REDAKSI \\ KATA PENGANTAR \\ DAFTAR ISI}

\section{DAFTAR ISI}

Etika Otonomi Daerah Dalam Perspektif Filsafat Pendidikan

Oleh:

Fatmawati

Peranan Aparatur Pusat Penelitian dan Pengembangan Daya Air

(Puslitbang SDA) dalam Meningkatkan Kualitas Pelayanan Publik Melalui Sistem Informasi Geografis Bidang Sumber Daya Air (SIGSDA)

Oleh:

Henri Prianto Sinurat

Revitalisasi Pembangunan Pendidikan Melalui

Pendekatan Komunikasi Pendidikan

Oleh:

Iwan Koswara

Monitoring dan Evaluasi Pemanfaatan Dana Keistimewaan Daerah

$60-91$

Istimewa Yogyakarta Tahun 2013-2017

Oleh:

Laksmi Nurita Tanjung, Dyah Mutiarin dan Eko Priyo Purnomo

Mekanisme Lembaga Adat Melayu Riau dalam Melestarikan Wisata Budaya di Provinsi Riau.

Oleh:

M.Zainuddin

Implementasi Fungsi Artikulasi dan Agregasi PKS Kota Bandung pada Pemilu 2009.

Oleh:

Olih Solihin 


\title{
ETIKA OTONOMI DAERAH DALAM PERSPEKTIF FILSAFAT PENDIDIKAN
}

\author{
Fatmawati $^{1}$ \\ fatmawatipuaupa@yahoo.com
}

\begin{abstract}
ABSTRAK
Tuntutan perbaikan pemerintahan daerah ini sebagai akibat dari efek adanya gerakan Reformasi pada 1998 sejak Pemerintahan Suharto dilengserkan oleh gerakan mahasiswa yang ingin adanya perubahan dalam kehidupan berbangsa, bermasyarakat, dan bernegara. Penulis melakukan metode penelitian menggunakan penulisan deskriptif berdasarkan studi kepustakaan tentang etika otonomi daerah dalam perspektif filsafat pendidikan. Tujuan Pendidikan Nasional itu sendiri adalah mencerdaskan kehidupan bangsa dan mengembangkan manusia Indonesia seutuhnya, yaitu manusia yang beriman dan bertaqwa kepada Tuhan Yang Maha Esa dan berbudi pekerti luhur, memiliki pengetahuan dan keterampilan, kesehatan jasmani dan rohani, kepribadian yang mantap dan mandiri serta rasa tanggungjawab kemasyarakatan dan kebangsaan yang berdasarkan falsafah Pancasila dan UUD 1945.

Filsafat, jika dilihat dari fungsinya secara praktis adalah sebagai sarana bagi manusia untuk dapat memecahkan berbagai problematika kehidupan yang dihadapinya, termasuk dalam problematika di bidang pendidikan. Oleh karena itu, apabila dihubungkan dengan persoalan pendidikan secara luas, dapat disimpulkan bahwa filsafat merupakan arah dan pedoman atau pijakan dasar bagi tercapainya pelaksanaan dan tujuan pendidikan. Jadi, filsafat pendidikan adalah ilmu yang pada hakikatnya merupakan jawaban dari pertanyaan-pertanyaan dalam bidang pendidikan yang merupakan penerapan analisis filosofi dalam lapangan pendidikan (Jalaluddin \& Abdullah Idi, 2012: 9). Filsafat pendidikan ini berkaitan dengan manusia, filsafat, dan pendidikan. Karena itu, etika otonomi daerah dalam perspektif filsafat pendidikan ini berkenaan dengan bidang kajian ontologi, epistemologi, dan aksiologi, yaitu tentang tujuan, hakikat, dan manfaat pendidikan bagi sumber daya manusia sebagai landasan etika otonomi daerah.

Dengan demikian, maka etika otonomi daerah berkaitan dengan manusia, filsafat, dan pendidikan. Etika menurut KBBI (Kamus Besar Bahasa Indonesia) adalah ilmu tentang apa yang baik dan apa yang buruk dan tentang hak dan kewajiban moral (akhlak). Etika otonomi daerah dalam perspektif filsafat pendidikan, hal ini berhubungan dengan etika manusia dalam kepemimpinan yang terbentuk melalui proses pendidikan karena tujuan pendidikan itu sendiri adalah baik.
\end{abstract}

Kata Kunci: Etika, Otonomi Daerah, Filsafat Pendidikan

\section{ABSTRACT}

The demands for the improvement of this regional government as a result of the effect of the Reformation movement in 1998 since the Suharto Government were ousted by the student movement that wanted to change in the life of the nation,

\footnotetext{
${ }^{1}$ Dosen IP dan Puket II Bidang Administrasi Keuangan STISIP Syamsul Ulum Kota Sukabumi
} 
the society and the state. The author conducted a research method using descriptive writing based on literature studies on regional autonomy ethics in the perspective of educational philosophy. The purpose of National Education itself is to educate the life of the nation and develop a complete humanity of Indonesia, the man who believes and piety to God Almighty and virtuous noble character, possessing knowledge and skills, physical and spiritual health, a stable and independent personality and sense of responsibility. the responsibility of society and nationality based on the philosophy of Pancasila and the 1945 Constitution.

Philosophy, when viewed from its function is practically as a means for human beings to be able to solve various problems of life faced, including in the problems in the field of education. Therefore, if it is related to the issue of education widely, it can be concluded that philosophy is the direction and guidance or basic foundation for the achievement of the implementation and objectives of education. Thus, the philosophy of education is a science that is essentially the answer to the questions in the field of education which is the application of philosophy analysis in the field of education (Jalaluddin \& Abdullah Idi, 2012: 9). This educational philosophy deals with human beings, philosophy, and education. Therefore, the ethics of regional autonomy in the perspective of educational philosophy is concerned with the field of ontology, epistemology, and axiology studies, namely the objectives, nature, and benefits of education for human resources as the foundation of ethics of regional autonomy.

Thus, the ethics of regional autonomy relate to human beings, philosophy, and education. Ethics according KBBI (Big Indonesian Dictionary) is the science of what is good and what is bad and about moral rights and obligations (morals). Ethics of regional autonomy in the perspective of educational philosophy, it is related to human ethics in leadership that is formed through the education process because the goal of education itself is good.

Keywords: Ethics, Regional Autonomy, Philosophy of Education

\section{PENDAHULUAN}

Konsep otonomi dalam konteks organisasi Pemerintahan Daerah melahirkan beragam pengertian walaupun dalam substansinya mengarah pada pengertian yang sama. Pengertian-pengertian yang berkembang sesuai dengan tuntutan kebutuhan yang dapat disebutkan antara lain oleh pakar dalam ilmu pemerintahan dirumuskan sebagai pengaturan sendiri yang ditujukan untuk keperluan wilayah atau bagian negara atau kelompok yang memerintah sendiri (Surianingrat, 1987) dalam (Faried Ali dan Andi Syamsu Alam, 2012: 151). Jelas bahwa otonomi daerah berkaitan erat dengan manusia dan kepemimpinan yang terbentuk dalam proses pendidikan.

Dalam pandangan Weber (2006) bahwa pemimpin dalam dirinya melekat kuat komitmen moral dan intelektual, pemimpin tidak memperlihatkan sikap yang 
memihak kepada salah satu kelompok - yang satu diistimewakan dan yang lain diabaikan. Pemimpin yang baik adalah pemimpin yang dapat memberi motivasi, semangat, optimisme, dan janji bagi perbaikan yang menyeluruh. Kepala Daerah adalah seorang pemimpin. Kalau kita bicara mengenai Kepala Daerah, pasti kita akan mencari seorang pemimpin yang amanah (baca Al-Qur'an tentang pemimpin yang amanah), seperti yang dijelaskan oleh Weber di atas.

Elit pemimpin dalam perspektif sosiologi dapat diartikan sebagai anggota masyarakat yang paling berbakat, karena elit itu lebih banyak ditujukan pada elit politik (political elite). Menurut David Jarry dan Julia Jarry (1991: 188) memberikan penekanan, bahwa teori elit yang membagi antara kaum elit dan rakyat jelata, merupakan ciri yang tidak bisa terelakkan dalam masyarakat modern yang kompleks di manapun berada. Menurut Syarifuddin Jurdi (2010: 50) asumsi yang mengatakan bahwa rakyat secara keseluruhan yang menjalankan pemerintahan adalah sesuatu yang keliru.

Pemerintah Negara Republik Indonesia dibentuk sesuai dengan cita-cita bangsa Indonesia, yaitu untuk melindungi segenap bangsa Indonesia dan seluruh tumpah darah Indonesia, memajukan kesejahteraan umum, mencerdaskan kehidupan bangsa dan ikut melaksanakan ketertiban dunia (baca Pembukaan UUD 1945 di alinea 2). Tugas pokok bangsa selanjutnya adalah menyempurnakan dan menjaga kemerdekaan itu serta isinya dengan pembangunan yang berkeadilan dan demokratis yang dilaksanakan secara bertahap dan berkesinambungan. Untuk menjamin agar kegiatan pembangunan efektif, efisien dan bersasaran maka diperlukan Perencanaan Pembangunan Nasional, agar dapat disusun Perencanaan Pembangunan Nasional yang dapat menjamin tercapainya tujuan Negara perlu adanya Sistem Perencanaan Pembangunan Nasional. (Undang-Undang Nomor 25/2004 tentang Sistem Perencanaan Pembangunan Daerah).

Kaitan demokrasi dan kesejahteraan sudah sejak lama menjadi perdebatan panjang di kalangan pakar ilmu politik dan ekonomi, dengan pertanyaan kembar: “Apakah demokrasi dapat mengantarkan pada kesejahteraan? Dan apakah demokrasi merupakan jalan tunggal menuju kemakmuran? Kesimpulan perdebatan tetap spekulatif-hipotesis karena bergantung pada sejumlah asumsi dasar dan persyaratan yang harus dipenuhi, agar demokrasi dapat memuluskan jalan 
mencapai kesejahteraan dan kemakmuran (Ed. Agus Pramusinto \& Wahyudi Kumorotomo, 2009: xiv).

Amich Al-Humami (Kompas, 2007) menyimpulkan bahwa hubungan demokrasi-kesejahteraan tak bersifat linear-kausalistik, melainkan non linearkondisional yang melibatkan banyak faktor, seperti pengalaman sejarah, basis sosial, struktur masyarakat, pendidikan penduduk, penegakan hukum, kemantapan/kelenturan institusi politik.

Kegemilangan ekonomi Korea Selatan dan Taiwan juga berawal dari sistem semiotoriter, sampai kedua negara itu memeluk demokrasi secara penuh. Vietnam yang de facto menganut sistem otoriter juga mendemontrasikan kinerja ekonomi yang menawan sejak pertengahan 1990-an. China adalah contoh lain, yang bereksperimen mengadaptasi sistem politik otoriter dengan menyerap sistem ekonomi pasar bebas, seperti dianut negara-negara demokrasi liberal. Eksperimen China berbuah pertumbuhan ekonomi yang mencengangkan dunia (Ed. Agus Pramusinto \& Wahyudi Kumorotomo, 2009: xv).

Kita tak ingin menjadi negara yang menindas hak hidup buruh dan anak serta melukai martabat manusia. Kita tak mau jadi negara yang hanya berpikir untuk menaikkan pendapatan. Kita harus jadi negara yang memprioritaskan kehidupan rakyat", demikian pidato Presiden Venezuela Hugo Chavez, yang menjiwai Revolusi Bolivarian yang dicanangkannya. Evo Morales, Presiden Bolivia, juga mengucapkan hal yang sama", kita harus mendirikan negara yang bermartabat, negeri dimana rakyatnya yang miskin dilindungi, dihargai, dan dimuliakan”. Betapa agung pidato itu kalau yang mengucapkannya adalah pemimpin kita. Chavez dan Morales juga terpilih menjadi presiden lewat pemilihan yang demokratis. Kedua pemimpin Amerika Latin itu telah membuktikan ada jalan lain menuju kesejahteraan rakyat (Ed. Agus Pramusinto \& Wahyudi Kumorotomo, 2009: xvi), tanpa harus mengadopsi demokrasi liberal ala Barat dan Amerika.

Otonomi daerah selayaknya bisa memberikan manfaat pertumbuhan ekonomi masyarakat desa yang lebih sehat dengan memperhatian faktor-faktor ke daerahan (kearifan lokal), seperti pengalaman sejarah, basis sosial, struktur masyarakat, pendidikan penduduk, penegakan hukum, kemantapan/kelenturan institusi politik, dan adat istiadat penduduk desa yang ada di daerah-daerah 
Indonesia. Demokrasi tidak mampu menjamin adanya pembangunan kesejahteraan masyarakat pedesaan. Karena banyak faktor yang mempengaruhi jalannya otonomi daerah secara baik dan benar.

Para ekonom mulai menyadari bahwa daerah pedesaan pada umumnya dan sektor pertanian pada khususnya ternyata tidak hanya bersifat positif tetapi jauh lebih penting dari sekedar penunjang dalam proses pembangunan ekonomi secara keseluruhan. Salah satu cara untuk membangun perekonomian nasional suatu negara adalah dengan cara membangun sektor pertanian dan daerah pedesaan itu dengan baik.

Tidak dapat dipungkiri bahwa sektor pertanian dan pedesaan dapat membantu meningkatkan perekonomian nasional. Hal ini sudah dibuktikan oleh negara-negara maju seperti Amerika Serikat (AS), Inggris, Kanada, dan Jepang. Negara-negara tersebut membuktikan bahwa pembangunan sektor pertanian dan pedesaan mereka dapat membantu perekonomian nasional mereka dengan memberikan kontribusi bagi perekonomian selain sektor industri yang sudah menjadi sektor andalan dalam perekonomian mereka. Berbagai kontribusi yang bisa diberikan meliputi: (1) Peningkatan lapangan pekerjaan sehingga secara otomatis akan menurunkan tingkat angka pengangguran, (2) Untuk menekan tingginya tingkat urbanisasi di negara itu, (3) Sebagai penyeimbang dalam pertumbuhan sektor industri.

Etika otonomi daerah dalam perspektif filsafat pendidikan fokus kepada pembangunan dan pemberdayaan sumber daya manusia karena filsafat pendidikan ini meliputi manusia, filsafat, dan pendidikan itu sendiri. Pembangunan dan pemberdayaan sumber daya manusia di daerah otonom berkaitan erat dengan manajemen sumber daya manusia yang berkualitas (MSDM).

Menurut Yusron (2009: 97-98) Demokrasi adalah jalan yang telah dipilih bangsa ini untuk mencapai tujuan hidup berbangsa dan bernegara. Tidak terkecuali di tingkat lokal pun, semua proses politik harus berada dalam koridor demokrasi. Hal yang menjadi persoalan sekarang adalah bagaimana mengkonsolidasikan semua pihak yang terkait dengan proses demokrasi lokal agar benar-benar terkonsolidasi dengan baik. Tanpa ada konsolidasi seluruh aktor demokrasi, maka akan mengundang masuknya pimpinan yang tirani. Lebih dari itu, akan 
menimbulkan gerakan yang kontraproduktif. Dengan konsolidasi yang baik, maka rakyat akan bebas memunculkan wacana publik, berpendapat, dan berkumpul. Hal yang tidak kalah penting adalah adanya kesadaran bahwa demokrasi merupakan alat untuk mencapai tujuan hidup berbangsa dan bernegara yaitu masyarakat yang adil dan makmur. Dengan demikian demokrasi harus bisa mengurangi kemiskinan, mengurangi pengangguran, mengurangi kebodohan, meningkatkan kemakmuran, meningkatkan derajat kesehatan dan menjamin keamanan rakyat. Demokrasi harus bisa menjaga dan meningkatkan keberlanjutan pembangunan di segala bidang kehidupan rakyat kecil, termasuk pembangunan manajemen sumber daya manusia yang berkualitas lahir dan batin.

Oleh karena itu, demokrasi ini melahirkan banyak daerah-daerah otonom yang tujuannya adalah membangun perekonomian masyarakat daerah setempat, pemberdayaan sumber daya manusia masyarakat daerah, dan mengurangi kemiskinan, mengurangi pengangguran, mengurangi kebodohan, dan meningkatkan kemakmuran, meningkatkan derajat kesehatan dan menjamin keamanan rakyat. Demokrasi harus bisa menjaga dan meningkatkan keberlanjutan pembangunan di segala bidang kehidupan rakyat kecil di daerah-daerah sehingga terwujudnya kemandirian perekonomian nasional yang lebih adil, merata, beradab, dan berperikemanusiaan. Karena itu, maka dikeluarkanlah Undang-Undang Republik Indonesia No. 32 Tahun 2004 tentang Pemerintahan Daerah.

Sistem pendidikan nasional juga menekankan pada demokrasi dan tidak ada diskriminasi dalam pendidikan. Semua warganegara memiliki hak yang sama untuk memperoleh pendidikan yang layak sesuai dengan cita-cita bangsa Indonesia, yaitu mencerdaskan kehidupan bangsa. Maknanya, negara memiliki kewajiban untuk penyelenggaraan pendidikan untuk semua warganegara.

Pendidikan diupayakan dengan berawal dari manusia apa adanya (aktualisasi) dengan mempertimbangkan berbagai kemungkinan yang apa adanya (potensialitas), dan diarahkan menuju terwujudnya manusia yang seharusnya atau manusia yang dicita-citakan (idelitas). Tujuan pendidikan itu tiada lain adalah manusia yang beriman dan bertakwa kepada Tuhan YME, berakhlak mulia, sehat, cerdas, berperasaan, berkemauan, dan mampu berkarya, mampu memenuhi berbagai kebutuhan secara wajar, mampu mengendalikan hawa nafsunya, 
berkepribadian, bermasyarakat dan berbudaya. Implikasinya, pendidikan harus berfungsi untuk mewujudkan (mengembangkan) berbagai potensi yang ada pada manusia dalam konteks dimensi keberagaman, moralitas, individualitas/personalitas, sosialitas dan keberbudayaan secara menyeluruh dan terintegrasi. Dengan kata lain, pendidikan berfungsi memanusiakan manusia (Darda Syahrizal \& Adi Sugiarto, 2013: 6-7).

\section{KERANGKA PEMIKIRAN}

Penulis menggunakan landasan psikologi pendidikan, yaitu berkisar kepada proses pendidikan yang melibatkan guru (pendidik), peserta didik, dan staf kependidikan dan tujuan pendidikan itu sendiri. Menurut Nana Syaodih Sukamadinata (2003: 4-5) Perbuatan mendidik diarahkan pada pencapaian tujuantujuan tertentu, yaitu tujuan pendidikan. Tujuan-tujuan ini bisa menyangkut kepentingan peserta didik sendiri, kepentingan masyarakat dan tuntutan lapangan pekerjaan atau ketiga-tiganya peserta didik, masyarakat dan pekerjaan sekaligus. Proses pendidikan terarah pada peningkatan penguasaan pengetahuan, kemampuan, keterampilan, pengembangan sikap dan nilai-nilai dalam rangka pembentukan dan pengembangan diri peserta didik. Pengembangan diri ini dibutuhkan untuk menghadapi tugas-tugas dalam kehidupannya sebagai pribadi, sebagai siswa, karyawan, profesional maupun sebagai warga masyarakat.

Sasaran dan perbuatan pendidikan selalu normatif, selalu terarah kepada yang baik. Perbuatan pendidikan tidak mungkin dan tidak pernah diarahkan kepada pencapaian tujuan-tujuan yang merugikan atau bertentangan dengan kepentingan peserta didik ataupun masyarakat. Perbuatan pendidikan selalu diarahkan kepada kemaslahatan dan kesejahteraan peserta didik dan masyarakat. Karena tujuannya positif maka proses pendidikannya juga harus selalu positif, konstruktif, normatif. Tujuan yang normatif tidak mungkin dicapai dengan perbuatan yang tidak normatif pula. Oleh karena itu, kepada guru sebagai pendidik dituntut untuk selalu berbuat, berperilaku, berpenampilan sesuai dengan norma-norma. Sering terjadi perbuatan yang bagi petugas lain tetapi bagi guru kurang wajar, umpamanya menambah penghasilan dengan cara "ngojeg", menarik becak, bahkan berdagang pun adakalanya dianggap kurang wajar bagi guru. 
Landasan teori psikologi pendidikan ini berintikan interaksi antara guru (pendidik) dengan peserta didik dalam proses pembelajaran dan pendidikan guna mencerdaskan kehidupan bangsa sehingga pencapaian-pencapaian tujuan pendidikan itu sendiri dapat mereduksi manajemen sumber daya manusia yang berkualitas sebagai faktor utama dan pegang peranan penting dalam beretika otonomi daerah guna tercapainya cita-cita bangsa Indonesia, yaitu mencerdaskan kehidupan bangsa dan memajukan kesejahteraan umum. Itulah yang disebut dengan Etika Otonomi Daerah Dalam Perspektif Filsafat Pendidikan.

\section{UUD 1945 Amandemen tentang Pendidikan \\ BAB XIII PENDIDIKAN DAN KEBUDAYAAN}

\section{Pasal 31}

1. Setiap warga negara berhak mendapat pendidikan.

2. Setiap warganegara wajib mengikuti pendidikan dasar dan pemerintah wajib membiayainya.

3. Pemerintah mengusahakan dan menyelenggarakan satu sistem pendidikan nasional, yang meningkatkan keimanan dan ketakwaan serta akhlak mulia dalam rangka mencerdaskan kehidupan bangsa, yang diatur dengan undang-undang. 4. Negara memprioritaskan anggaran pendidikan sekurang-kurangnya dua puluh persen dari anggaran pendapatan dan belanja negara serta dari anggaran pendapatan dan belanja daerah untuk memenuhi kebutuhan penyelenggaraan pendidikan nasional.

5. Pemerintah memajukan ilmu pengetahuan dan teknologi dengan menunjang tinggi nilai-nilai agama dan persatuan bangsa untuk kemajuan peradaban serta kesejahteraan umat manusia.

\section{HASIL DAN PEMBAHASAN}

Menurut Nana Syaodih Sukmadinata (2003: 29) interaksi pendidikan mempunyai suatu ciri dan fungsi khusus, yaitu bersifat dan berfungsi membantu perkembangan siswa. Manajemen sumber daya manusia yang ingin dibangun oleh etika otonomi daerah harus berlandaskan pada proses pendidikan yang melibatkan guru dan peserta didik. Seorang kepala daerah terbentuk dan terpilih karena memiliki kemampuan yang melebihi warganya sendiri. Karakter kepala daerah ini dibangun dan terbentuk oleh adanya pendidikan karakter peserta didik sejak awal ia di sekolah. 
Tujuan pendidikan yang ingin dicapai merupakan faktor yang menentukan kurikulum dan isi pendidikan yang diberikan. Selain itu, tujuan pendidikan dapat mempengaruhi strategi pemilihan teknik penyajian pendidikan yang dipergunakan untuk memberikan pengalaman belajar pada anak didik dalam mencapai tujuan pendidikan yang sdh dirumuskan. Dengan kurikulum dan isi pendidikan inilah kegiatan pendidikan dapat dilaksanakan secara benar seperti yang telah dirumuskan (Jalaluddin \& Abdullah Idi, 2012: 148).

Selanjutnya menurut Jalaluddin dan Abdullah Idi (2003: 148-149) Antara tujuan dan program harus ada keserasian. Tujuan yang hendak dicapai itu harus tergambar dalam program yang tertuang dalam kurikulum, bahkan program itulah yang mencerminkan arah dan tujuan yang ingin dicapai dalam proses pendidikan. Oleh karena itu, kurikulum merupakan faktor yang sangat penting dalam proses pendidikann dalam suatu lembaga kependidikan. Segala hal yang harus diketahui, diresapi dan dihayati oleh anak didik haruslah ditetapkan dalam kurikulum. Dan, segala hal yang harus dijabarkan dalam kurikulum. Kurikulum tersebut menggambarkan secara jelas bagaimana dan apa saja yang harus dilakukan pendidik dan anak didik dalam proses belajar mengajar. Jadi, kurikulum itu menggambarkan kegiatan belajar mengajar dalam suatu lembaga pendidikan.

Otonomi daerah ini harus dibangun dengan manajemen sumber daya manusia yang profesional dan berkualitas. Desentralisasi ini mencakup pula desentralisasi pendidikan dalam tatanan etika otonomi daerah. Kepemimpinan dan sumber daya manusia yang profesional dan berkualitas terbentuk oleh pembangunan dan pemberdayaan sumber daya manusia yang baik, profesional dan berkualitas. Tanpa itu, pelaksanaan otonomi daerah dalam rangka tercapainya citacita bangsa, yaitu mencerdaskan kehidupan bangsa dan memajukan kesejahteraan umum hanya sebagai slogan-slogan saja yang tidak bermakna.

UU Otonomi Daerah oleh Pemerintah dan DPR disepakati untuk disahkan maka pada 1999, yaitu UU No. 22/1999 dan No. 25/1999. Dengan diberlakukannya otonomi daerah, maka wewenang untuk mengurus daerah sendiri mulai dirancang oleh masing-masing daerah. Seiring dengan implementasi otonomi daerah, sektor pendidikan yang merupakan salah satu sektor pelayanan dasar, juga mengalami perubahan mendasar baik dari segi birokrasi kewenangan penyelenggaran 
pendidikan maupun dari aspek pendanaannya. Ketika UU No. 22/1999 dan No. 25/1999 diberlakukan dan disusul dengan kebijakan Departemen Pendidikan Nasional tentang sistem manajemen berbasis sekolah dan pemberian kewenangan terhadap daerah (bahkan sekolah) dalam mengelola pendidikan, timbul secercah harapan akan semakin membaiknya pembangunan pendidikan. Model pembangunan pendidikan yang sangat bersifat sentralistik dan monolitik serta menafikan perbedaan, secara drastis mestinya berubah menjadi desentralistik dan pluralistik sehingga kepentingan dan kebutuhan serta potensi dan kemampuan daerah menjadi lebih terperhatikan dan terbangkitkan. Dengan desentralisasi pendidikan yang direpresentasikan melalui model pengelolaan Manajemen Berbasis Sekolah dan Manajemen Berbasis Masyarakat, segenap komponen sekolah menjadi semakin berperan. Penyusunan kurikulum nasional yang harus memperhatikan akar budaya atau kearifan lokal dan kebutuhan masyarakat setempat, dengan pemberian kewenangan besar kepada daerah tanpa diskriminasi pendidikan dan semua warganegara memiliki hak yang sama untuk memperoleh pendidikan yang layak untuk masa depannya, masyarakat, bangsa dan negara.

Desentralisasi pendidikan merupakan salah satu model pengelolaan pendidikan yang menjadikan sekolah sebagai proses pengambilan keputusan dan merupakan salah satu upaya untuk memperbaiki kualitas pendidikan serta sumber daya manusia termasuk profesionalitas guru yang belakangan ini dirisaukan oleh berbagai pihak baik secara regional maupun secara internasional (Hadiyanto, 2004: $63)$.

\section{KESIMPULAN}

Bahwa pelaksanaan otonomi daerah yang berawal dengan tujuan untuk membangun daerah setempat harus memiliki landasan etika otonomi daerah dalam perspektif filsafat pendidikan yang jelas dan terarah. Karena, pembangunan dan pemberdayaan sumber daya manusia yang baik, profesional dan bermutu menunjukkan suatu keserasian dan kesesuaian dengan etika otonomi daerah dalam perspektif filsafat pendidikan. Para ahli pendidikan telah sepakat bahwa membangun manajemen sumber daya manusia harus melalui proses pembelajaran dan pendidikan yang baik, efektif, efisien, dan profesional tanpa diskriminasi dan 
semua warganegara memiliki hak yang sama untuk memperoleh pendidikan yang layah sesuai dengan UUD 1945 Pasal 31.

\section{DAFTAR PUSTAKA}

Darda Syahrizal \& Adi Sugiarto, Undang-Undang Sistem Pendidikan Nasional \& Aplikasinya, (Jakarta, Laskar Aksara, Cet.1, 2013).

Faried Ali dan Andi Syamsu Alam, Studi Kebijakan Pemerintahan, (Bandung: Refika Aditama, cetakan kesatu, Januari 2012).

Hadiyanto, Mencari Sosok Desentralisasi Manajemen Pendidikan di Indonesia, (Jakarta: Rineka Cipta, 2004).

Governance Reform di Indonesia: Mencari Arah Kelembagaan Politik yang Demokratis dan Birokrasi yang Profesional, (Ed. Agus Pramusinto \& Wahyudi Kumorotomo), Yogyakarta: Gava Media-MAP UGM, Cetakan pertama, 2009.

Jalaluddin \& Abdullah Idi, Filsafat Pendidikan: Manusia, Filsafat, dan Pendidikan, (Jakarta: RajaGrafindo Persada, Cetakan ke-2, Maret 2012).

Jurdi, Syarifuddin., Sosiologi Islam dan Masyarakat Modern: Teori, Fakta, dan Aksi Sosial, Jakarta: Kencana Prenada Media Group, Ed. I, Cetakan Pertama, Februari, 2010.

Jarry, David dan Jarry, Julia., Collins Dictionary of Sosiology, (Glasgow, Harper Collins Publishers, 1991).

Sukmadinata, Nana Syaodih., Landasan Psikologi Proses Pendidikan, (Bandung: PT Remaja Rosdakarya, Cetakan pertama, Mei 2003).

Yusron, Elite Lokal dan Civil Society: Kediri di Tengah Demokratisasi, Jakarta: LP3ES, Cetakan Pertama, Februari 2009.

Weber, Max., The Protestant Ethic and the Spirit of Capitalism, diterjemahkan oleh Talcot Parsons, (New York: Charles Scribner's Son, 1958): "Bureaucrazy", dalam H. Gert dan C.W. Mills (ed.), Max Weber: Essays in Sosiology, Oxford, UK, Oxford University Press 1946, Sosiologi (Yogyakarta: Pustaka Pelajar, 2006).

Amich Al-Humami, "Mitos Demokrasi untuk Kesejahteraan", Kompas, 27 Desember 2007 dikutip dari buku Governance Reform di Indonesia. 